\title{
AS TECNOLOGIAS MÓVEIS DIGITAIS DA INFORMAÇÃO E COMUNICAÇÃO PRESENTES NA FORMAÇÃO INICIAL DOCENTE EM CIÊNCIAS BIOLÓGICAS
}

\section{The Digital Mobile Information and Communication Technologies Present in the Initial Teaching Training in Biological Sciences}

\author{
Manoel Messias Santos Alves ${ }^{1}$ \\ Anne Alilma Silva Souza Ferrete ${ }^{2}$ \\ Willian Lima Santos ${ }^{3}$
}

\begin{abstract}
Resumo: O artigo teve como objetivo central compreender a percepção dos acadêmicos do Curso de Licenciatura em Ciências Biológicas, nas modalidades presencial e à distância, da Universidade Federal de Sergipe (UFS), sobre a utilização das Tecnologias Móveis Digitais da Informação e Comunicação (TMDIC) enquanto conhecimentos tecnológicos e pedagógicos desenvolvidos em seu processo de formação inicial. Para alcançar esse objetivo, buscou-se também conhecer o perfil relacionado à cultura digital dos licenciandos e investigar como esse público se sente em relação ao letramento digital docente. Corresponde a uma pesquisa de natureza qualitativa e com viés exploratório, da qual participaram três pesquisadores no processo de validação de um questionário, e foi realizado um estudo de caso com 33 (trinta e três) acadêmicos, distribuídos em 11 (onze) na modalidade presencial e 22 (vinte e dois) na Educação a Distância (EaD), sendo a maioria do último período da graduação. Foi constatado que todos os participantes concordaram que as TMDIC contribuem para a aprendizagem dos educandos, desde que sejam utilizadas adequadamente dentro e fora da sala de aula. A maioria dos participantes afirmou possuir níveis satisfatório e avançado de conhecimentos e habilidades sobre a utilização dessas tecnologias em seu cotidiano, apontando, assim, uma interconexão desse público com o ciberespaço. No entanto, 27,3\% dos participantes relataram ausência de abordagens tecnológicas durante sua formação devido a uma série de fatores, dentre eles a falta de interesse dos professores e tutores da universidade, bem como a desmotivação da turma e a carência de recursos didáticos e tecnológicos.
\end{abstract}

Palavras-chave: Cultura digital. Formação docente. Letramento digital.

\footnotetext{
1 Doutorando em Educação (PPGED/UFS). Mestre em Ensino de Ciências (PPGECIMA/UFS). Bacharel em Enfermagem e Licenciado em Ciências Biológicas. Universidade Federal de Sergipe (UFS). Orcid iD: https://orcid.org/0000-0002-4070-1691. E-mail: messyarts@ hotmail.com.

2 Doutora em Educação. Professora da Universidade Federal de Sergipe (UFS), lotada no Departamento de Educação (DED), no Centro de Educação e Ciências Humanas $(\mathrm{CECH})$. Professora permanente do Programa de Pós-Graduação em Educação (PPGED). Orcid iD: https://orcid.org/0000-0001-9637-6616. E-mail: alilma.ferrete50@gmail.com.

${ }^{3}$ Mestrando em Educação (PPGED/UFS). Especialista em Tecnologias e Educação Aberta e Digital (UFRB). Pedagogo (FANEB). Orcid iD: https://orcid.org/0000-0002-9298-1226. E-mail: willianjere@ hotmail.com.
} 
Abstract: The main objective of the article was to understand undergraduate and distance learning students' perception of Biological Sciences Course, at the Federal University of Sergipe (FUS), about the use of Digital Mobile Information and Communication Technologies (DMICT) while technological and pedagogical knowledge developed their initial training process. To achieve this goal, we also sought to know the profile related to the digital culture of the undergraduate students and to investigate how this public felt about the teachers' digital literacy. It corresponded to a qualitative research with an exploratory bias, in which three researchers participated in the process of validating a questionnaire, and a case study was carried out with 33 (thirty-three) academics, distributed in 11 (eleven) personally and 22 (twenty-two) in Distance Education (DE), the majority being from the last period of undergraduate courses. It was found that all participants agreed that DMICT contributed to the students' learning, as long as they are used properly inside and outside the classroom. Most participants stated that they had satisfactory and advanced levels of knowledge and skills on the use of these technologies in their daily lives, thus pointing out an interconnection of this audience with cyberspace. However, $27.3 \%$ of the participants reported the absence of technological approaches during their training due to a number of factors, among them, the lack of interest from university professors and tutors, as well as demotivation of the class and lack of didactic and technological resources.

Keywords: Digital Culture. Teacher training. Digital literacy.

\section{Introdução}

A crescente expansão das Tecnologias Móveis Digitais da Informação e Comunicação (TMDIC), mediante os recursos de conexão sem fio dos serviços de telefonia móvel e conexão wireless, tem contribuído para que um número elevado de pessoas tenha acesso a uma variedade de dispositivos móveis, sobretudo a partir do início do século XXI, principalmente aos smartphones (telefones celulares com tecnologias avançadas), tendo suas vidas significativamente adaptadas a novas maneiras de aprender, pensar, agir e interagir no ciberespaço (LÉVY, 1999; SILVA; MORAES, 2014; LEMOS, 2015; MARINHO et al., 2015).

Mesmo considerando algumas barreiras socioeconômicas significativas na atualidade, convém ressaltar que, além do desenvolvimento das tecnologias de comunicação sem fio, outros fatores contribuíram para a popularização dos smartphones e dos demais dispositivos móveis, como o baixo custo de alguns modelos, em comparação aos computadores convencionais, e a fácil portabilidade devido a suas dimensões reduzidas, o que permite aos usuários transportálos consigo no dia a dia e ter acesso à internet em diferentes localidades onde existirem serviços de telefonia móvel ou conexão Wi-Fi (MARINHO et al., 2015).

Considerando o fato de que o processo de ensino e aprendizagem necessita de constante ressignificação, as discussões acerca do uso educacional das tecnologias vêm ganhando destaque nos cursos de formação docente, tanto inicial quanto continuada, tendo em vista que a maioria dos alunos tem acesso a diferentes dispositivos móveis na atualidade e inclusive os leva para a sala de aula, reforçando, assim, a importância de aprimorar ou desenvolver práticas didático-pedagógicas para que os professores se apropriem dessas tecnologias dentro e fora dos espaços educativos (BARCELOS, 2012; FERRETE A.; FERRETE R., 2014).

Nessa perspectiva, os desafios impostos à humanidade para o enfrentamento à pandemia da COVID-19 (novo coronavírus) no cenário atual, em que a principal medida a ser adotada a fim de diminuir a disseminação desse vírus é a restrição do contato físico entre as pessoas, 
principalmente por meio do distanciamento social, fizeram com que os serviços de home working (teletrabalho ou trabalho à distância) e de distance learning (ensino a distância) se popularizassem de modo nunca visto antes, tornando-se importantes estratégias para garantir a manutenção dos serviços essenciais e o acesso a eles. No que se refere ao âmbito escolar, a integração dessas tecnologias tem buscado promover a construção de novas possibilidades no processo de ensino e aprendizagem, com isso nos desperta o interesse de se investigar qual o nível do conhecimento tecnológico e pedagógico ofertado aos professores durante sua formação inicial para que se sintam seguros em desenvolver sua prática docente nesse contexto de ensino remoto emergencial.

Buscamos, como objetivo geral deste estudo, compreender a percepção dos acadêmicos de duas turmas do Curso de Licenciatura em Ciências Biológicas, uma da modalidade presencial e outra da Educação à Distância (EaD), da Universidade Federal de Sergipe (UFS), sobre a utilização das Tecnologias Móveis Digitais da Informação e Comunicação (TMDIC) enquanto conhecimentos tecnológicos e pedagógicos desenvolvidos em seu processo de formação inicial. Para alcançar esse objetivo, procuramos também conhecer o perfil relacionado à cultura digital dos licenciandos e investigar como esse público se sente em relação ao letramento digital docente. Essa discussão se mostra relevante diante das tendências e da necessidade de adaptação à atual sociedade digital, sobretudo em tempos de pandemia, para investigar se a formação inicial ofertada a esses futuros docentes tem enfatizado a prática pedagógica no tocante ao letramento digital.

As discussões levantadas neste trabalho podem parecer complexas, porém são atuais e importantes à medida que se propõem refletir sobre as limitações e as possibilidades das relações existentes entre professores, ensino e tecnologias, desenvolvidas no decorrer da formação inicial para enfrentar os possíveis desafios existentes na sociedade tecnológica, chamada por Castells (1999) de 'Sociedade em Rede'. Dentre esses desafios relacionados à presença da tecnologia nas práticas educativas, destaca-se a necessidade de uma formação contínua para os professores, voltada ao uso das TMDIC, e a integração delas no currículo escolar com enfoque na cultura digital, ou 'cibercultura', como preferem chamar Lévy (1999) e Lemos (2015).

\section{As tecnologias na cultura digital: aspectos gerais em tempos de pandemia}

O significado do termo tecnologia está em constante evolução, fazendo-se necessário superar a equivocada ideia propagada no decorrer dos anos de que a tecnologia se restringe aos diferentes recursos e equipamentos eletrônicos ou digitais de última geração. Está cada vez mais evidente perceber o quanto as ações cotidianas estão conectadas com os mais variados recursos digitais, principalmente nos dias atuais devido ao enfrentamento à COVID-19, que, em caráter emergencial, fez flexibilizar e incorporar o uso de tais recursos.

No decorrer dos anos, surgiram importantes descobertas que deram origem às mais variadas tecnologias, cada uma no seu tempo, e, de maneira geral, objetivaram atender às demandas sociais e capitalistas das diferentes épocas. Recentemente, o emprego das tecnologias transmite a ideia de conforto, praticidade e facilidade, mas não podemos negar que tais inovações acontecem de maneira rápida e, de certa forma, obrigam - ou pelo menos condicionam - os indivíduos a viverem em constante aperfeiçoamento e aquisição de habilidades para manuseá-las, pois muitas pessoas acabam se tornando cada vez mais dependentes desses elementos (TEIXEIRA, 2011). 
Embora a possibilidade de realizar atividades a distância não seja algo exclusivamente recente na Educação Básica brasileira, pois, há mais de duas décadas, a Lei de Diretrizes e Bases da Educação Nacional (LDBEN), Lei no 9.394 de 1996, já autorizava essa modalidade como complementação da aprendizagem ou em situações emergenciais, e, mais recentemente, a Base Nacional Comum Curricular $(\mathrm{BNCC})^{4}$ referente ao Ensino Médio demonstrou preocupação com os impactos e transformações sociais ocasionados pelas tecnologias, ao enfatizar em seu texto a necessidade de se promover e considerar a cultura digital dos educandos, ainda permanece a sensação de que somente com a pandemia da COVID-19 é que o tradicional modelo de ensino do nosso país está sendo rompido ou, pelo menos, adaptado a essa realidade emergente. Assim, o cenário brasileiro tem acompanhado a tendência mundial de fechamento das escolas e interrupção das aulas presenciais, tanto da rede pública quanto da privada, e incentivado a implementação de atividades pedagógicas nos formatos a distância, por meio de plataformas on-line, com aulas síncronas ou assíncronas, envio de materiais digitais aos alunos nas redes sociais e demais estratégias que vêm sendo chamadas popularmente de ensino remoto emergencial.

Nessa perspectiva, após mais de seis meses de suspensão das aulas presenciais, o Conselho Nacional de Educação (CNE) resolveu aprovar, no dia 06 de outubro, um documento que defende estender a continuidade do ensino remoto até dezembro de 2021 e, inclusive, a junção dos anos letivos de 2020 e 2021; no entanto, esse texto precisa ainda ser homologado pelo MEC, mas suas diretrizes pretendem englobar desde a Educação Básica até o Ensino Superior, nas esferas pública e privada. Entretanto, essas medidas não serão obrigatórias, e cada Estado e Município poderá aderir ou não a essas propostas, ou até mesmo adaptá-las conforme suas necessidades (OLIVEIRA, 2020).

No entanto, alertamos neste estudo que tais estratégias emergenciais para garantir a continuidade do ensino, se não forem devidamente pensadas e adequadas às diferentes realidades sociodemográficas e econômicas do país, podem ampliar ainda mais o risco de desigualdades de acesso à educação, tendo em vista que a disposição de recursos tecnológicos não é homogênea entre os estudantes, e aqueles que possuem melhores condições de acesso tendem a se beneficiar mais desses recursos e obter melhor desempenho acadêmico (CRUZ; BORGES; NOGUEIRA FILHO, 2020). Dessa forma, é importante frisar que esse ensino remoto não deve se restringir apenas a aulas on-line, e sim levar em consideração diferentes possibilidades de estimular a aprendizagem de maneira estruturada, podendo fazer uso das plataformas digitais, mas sobretudo buscar diversificar as experiências de aprendizagem, promover a inclusão e valorizar o envolvimento das famílias nesse processo.

Nesse toar, Teixeira (2011) e Gewehr (2016) apontam que o ritmo acelerado em que as mudanças e inovações tecnológicas ocorrem tem despertado importantes impactos culturais, científicos e educacionais, exigindo, assim, novos modelos de análise e de adaptação a essa realidade nos diferentes contextos sociais, inclusive no âmbito escolar. Por esse motivo, não podemos ignorar as possibilidades e os desafios do uso das tecnologias no processo de ensino e de aprendizagem, sobretudo das tecnologias móveis, tendo em vista suas potencialidades pedagógicas.

Ao relacionar essa discussão com as consequências trazidas pelo enfrentamento ao novo coronavírus, juntamente com a necessidade de distanciamento social, percebemos o quanto as

\footnotetext{
${ }^{4}$ Enfatiza a necessidade de se promover conhecimentos, habilidades, valores e atitudes voltados às diferentes dimensões das tecnologias digitais, como o pensamento computacional, o mundo digital e a cultura digital. Para aprofundamento dessa discussão, recomendamos a leitura da quinta competência, "Cultura digital", da BNCC para o Ensino Médio (BRASIL, 2018).
} 
TMDIC têm encurtado esse distanciamento, pois, na maioria das vezes, as relações sociais estão sendo mantidas mesmo com o distanciamento físico. E, na esfera educativa, o avanço da educação digital e on-line contribui para que as atividades de ensino e a aprendizagem ultrapassem as barreiras físicas da escola, inclusive mediadas por interfaces disponíveis na internet consideradas informais, como apontam Santos, Ferrete e Alves (2020, p. 4), podendose citar o próprio Facebook, que, desde que em consonância com objetivos pedagógicos, "pode contribuir significativamente para o andamento do processo de ensino-aprendizagem, considerando as diferentes ferramentas disponíveis na web e suas funcionalidades", principalmente no compartilhamento de ideias, arquivos de mídia e links, na criação de comunidades, chats, videoconferências, entre outras possibilidades.

A associação desses recursos com as mídias digitais em geral favorece as relações de comunicação entre rede e mídia social, expressas na maioria das vezes através de textos, hipertextos, sons, imagens, vídeos, gráficos etc., que permitem uma interface de novas formas de expressão do indivíduo com o mundo digital (CASTELLS, 1999; TEIXEIRA, 2011). Buscando compreender as relações existentes entre o ser humano, a tecnologia e a cultura, Lévy (1999) e Lemos (2015) apresentam importantes contribuições acerca da cibercultura (cultura digital) como uma nova relação entre as tecnologias com a sociedade conectada e colaborativa, ancorada nos múltiplos recursos e possibilidades da internet.

Vale a pena lembrar que, embora a origem da internet tenha ocorrência histórica na década de 1960, com a Guerra Fria, sua expansão ocorreu de forma acelerada, juntamente com o desenvolvimento das tecnologias interativas, na última década do século passado. Esse fenômeno tecnológico, cuja finalidade inicial voltava-se a fins militares, passou por várias revoluções e, atualmente, como ressaltado, está presente no convívio social das pessoas, repercutindo em transformações socioeconômicas e socioculturais, pois, segundo Lemos (2015, p. 13), a "internet encarna a presença da humanidade e a ela própria, já que todas as culturas, todas as disciplinas, todas as paixões aí se entrelaçam".

É importante considerar que a Grande Rede Mundial (World Wide Web), ou, simplesmente, $W e b$, corresponde a um ambiente social de interações por meio de hipertextos e de multimídias capazes de possibilitar aos usuários uma maior interação e conectividade com emissores, conforme suas necessidades e seus interesses (GARCIA, 2010). Dessa forma, o conceito de $W e b$ se entrelaça com a própria evolução da cibercultura e das TMDIC, tendo em vista suas configurações e possibilidades de integração na grande rede mundial, a Web 2.0, que, por sua vez, está passando por novas transformações, podendo até mesmo se pensar numa projetação para uma nova Web, denominada previamente de "Web 3.0", tendo como diferencial a cooperação existente na relação entre humanos e computadores (MATTAR, 2008; GEWEHR, 2016).

Nesse sentido, a cultura contemporânea contempla uma relação simbiótica entre o homem, a natureza e a sociedade integrada às tecnologias digitais, a qual Lemos (2015) define como uma exemplificação de cibercultura, ou seja, uma nova forma de cultura que está presente em todas as atividades da vida diária, como podemos perceber na citação a seguir:

A análise da cibercultura [...] mostra que esta caracteriza-se por uma atitude social de apropriação criativa (vitalista, hedonista, presenteísta) das novas tecnologias. Exemplos dessa atitude entre nós: a febre dos jogos eletrônicos, a efervescência das agregações sociais no ciberespaço, o ativismo político de tecnoanarquistas, o hedonismo da raves, a potência dos vírus e o erotismo do cibersexo, entre outros (LEMOS, 2015, p. 269). 
Diante dessa discussão, as mídias e as redes sociais presentes na cibercultura adentram os mais variados ambientes, mostrando-se eficazes no atual cenário de crise de saúde pública que a humanidade está vivenciando, e não podemos ignorar as possibilidades e os desafios do uso das tecnologias no processo de ensino e aprendizagem, sobretudo das tecnologias móveis, tendo em vista suas potencialidades pedagógicas. Em face desses pressupostos, aprofundaremos, na seção seguinte, a discussão acerca das TMDIC no campo da educação.

\section{Implementação das TMDIC na educação: desafios e possibilidades}

Diferentemente da educação tradicional propagada no decorrer dos anos, a implementação das tecnologias digitais, e mais recentemente das tecnologias móveis, garantiu às pessoas o acesso aos diferentes meios de informação e comunicação, sem restrições de tempo e espaço (SANTAELLA, 1997; LUCENA, 2016). Corroborando essa discussão, Ferrete A. e Ferrete R. (2017a) apontam que os impactos causados pelo avanço tecnológico já são evidenciados na escola, onde os estudantes do século XXI estão cada vez mais inseridos no mundo virtual através das redes e mídias sociais, que, por sua vez, se mostram mais atraentes do que a convencional sala de aula com a utilização de caderno, livros, lousa, giz e aulas conduzidas através de metodologias expositivas. Esses impactos são percebidos há alguns anos e se intensificaram principalmente no atual momento de distanciamento social e, consequentemente, de busca e oferta de aulas e atividades on-line.

Todavia, a presença das TMDIC, de maneira geral, ainda se encontra em progressão na educação brasileira, pois, como apontam Ferrete A. e Ferrete R. (2017a), esses dispositivos passaram a ser introduzidos de modo tímido nos ambientes escolares por meio da implantação da informática e dos demais elementos relacionados à área de tecnologias na educação. Por esse e outros motivos, é notória a existência de alguns desafios relacionados à adequação do ambiente escolar para a integração das TMDIC em sua prática educativa, tendo em vista que a simples presença dos dispositivos móveis em sala de aula, até então, não era suficiente para promover a cultura digital nas instituições de ensino. Dentre as principais limitações, destacamse a necessidade de uma estrutura física adequada, capaz de proporcionar acesso de qualidade à rede, e, principalmente, uma reformulação no currículo escolar com ênfase na formação pedagógica inicial e continuada de professores e gestores, para garantir, assim, a qualidade e o dinamismo das práticas pedagógicas por meio da tecnologia (MARINHO et al., 2015; FERRETE A.; FERRETE R., 2017b).

No que diz respeito às práticas de ensino integradas às tecnologias móveis, Silva e Morais (2014) ressaltam a importância de se promover procedimentos didáticos que privilegiem a construção colaborativa dos conhecimentos mediada pela figura do professor, a fim de possibilitar experiências diversificadas de ensino e aprendizagem aos discentes com a utilização desses dispositivos. Assim, para um melhor aproveitamento do uso das tecnologias em sala de aula, o planejamento prévio e adequado é um fator fundamental para a incorporação de ações e atividades escolares integradas ao uso das tecnologias móveis digitais, podendo, inclusive, fazer transposição didática de plataformas informais, como a própria rede social Facebook, para despertar o interesse e o engajamento dos discentes nesse processo (FERRETE A.; FERRETE R., 2014; ULIANO, 2016; SANTOS; FERRETE; ALVES, 2020).

Para que as TMDIC proporcionem uma construção de saberes por meio de descobertas, aprimoramento e motivação no âmbito educacional, faz-se necessário, entre outros fatores, pensar e agir em rede para que o professor reconheça a importância desses instrumentos e os 
incorpore em suas práticas didático-pedagógicas, propagando, assim, a cultura digital (ULIANO, 2016). Dessa forma, é necessário também rever e refletir sobre as concepções de sociedade, de escola e de sujeito, suas relações com o currículo, a aprendizagem e o perfil do professor e do aluno, de maneira que a apropriação e a efetivação das TMDIC aconteçam nas práticas de ensino (FERRETE A.; FERRETE R., 2017b).

Apesar da evidente necessidade do atual sistema de educação de acompanhar as transformações sociais - sendo que boa parte delas está relacionada com os avanços tecnológicos, sobretudo com a disseminação do acesso à internet, implicando uma cultura digital cada vez mais presente no meio educacional -, é crescente o número de trabalhos que apontam limitações nos cursos de formação inicial de professores no tocante ao desenvolvimento de habilidades, conceitos e atitudes imprescindíveis à atuação docente incorporada ao uso das tecnologias para alcançar os objetivos educacionais (CIBOTTO; OLIVEIRA, 2013; SANTO; CARDOSO; SANTOS, 2018). Assim, discutiremos na sequência sobre a importância de o letramento digital ser enfatizado como conhecimento tecnológico e pedagógico no processo de formação inicial docente, para que, então, os educadores consigam unificar de maneira apropriada a cultura digital com o processo de ensino e aprendizagem.

\section{$4 \mathrm{O}$ conhecimento tecnológico e pedagógico no processo de letramento digital docente}

O letramento digital é um processo que está em constante construção no contexto moderno em que vivemos. E, no que se refere ao letramento digital docente, trata-se de uma questão estratégica de valorização desse profissional, tendo em vista a relevância do seu papel na formação de sujeitos críticos, reflexivos e participativos numa sociedade em que a produção de informação está cada vez mais consolidada por meio das plataformas digitais.

É notório que o uso crescente dos recursos audiovisuais, e das tecnologias em geral, vem contribuindo para diversificar os métodos de aprendizagem, proporcionando um grande volume de informação que circula rapidamente no meio social. Para acompanhar o ritmo acelerado dessa sociedade tecnológica, a escola não pode ignorar esse processo de letramento digital, o qual requer que os professores estejam preparados para atuar com competência diante dos diversos meios de difusão e promoção do conhecimento e da aprendizagem.

Nessa perspectiva, para acompanhar as mudanças proporcionadas pela tecnologia nos mais variados contextos socioculturais, a escola precisa engajar-se de maneira comprometida na formação de cidadãos capazes de lidar com os avanços tecnológicos de forma consciente e participativa, necessitando, assim, além do conhecimento, de uma reflexão acerca das suas linguagens e de sua utilização. Entretanto, para que esse processo se concretize, o seu corpo docente também necessita se apropriar dessas tecnologias, visando, assim, melhorar a produtividade e a interatividade com os estudantes, de maneira autônoma e engajada, com as peculiaridades da cultura digital (SANTOS; FERRETE; ALVES, 2020). Ao trazer essa discussão para o processo de formação docente, a problemática assume proporções ainda maiores, tendo em vista que muitas vezes os professores, em sua maioria imigrantes digitais, são 'forçados' a aprender e a acompanhar a linguagem digital presente na sociedade em rede.

Essa preocupação com a necessidade de aperfeiçoamento docente acerca dos saberes e tendências pedagógicos não é algo recente. Desde a década de 1980 Shulman (1987) já mostrava interesse em repensar a formação docente da época, em que, ao invés de uma vertente exclusivamente, ou predominantemente, tecnicista, se deveria contemplar uma inerente integração entre os conhecimentos pedagógicos dos conteúdos (Pedagogical Content Knowledge - PCK), ou seja, por meio de transposição didática para promover uma inter-relação 
do conteúdo e da pedagogia adaptada às singularidades dos estudantes (ROCHA; SALVI, 2016). Com o passar dos anos, esse debate foi ganhando forças e teve suas abordagens ampliadas com os avanços tecnológicos, resultando, assim, no entrelaçamento dos conhecimentos nos eixos pedagógico, tecnológico e do conteúdo. Esse modelo teórico foi proposto inicialmente por Mishra e Koehler (2006) e ficou conhecido como Conhecimentos Tecnológicos e Pedagógicos dos Conteúdos (TPACK) ${ }^{5}$.

Diante da importância de uma formação para que as pessoas possam interpretar e interagir de maneira crítica junto com as mais variadas formas de comunicação, consideramos relevante, neste estudo, a possibilidade de investigar se a formação inicial de professores de ciências e/ou biologia, ofertada por uma universidade federal, tem se esforçado para capacitar seus futuros educadores acerca dos TPACK, de modo que se sintam seguros em utilizar pedagogicamente as tecnologias móveis em sua prática docente. De acordo com Sampaio e Leite (1999), esse processo pode ser compreendido também como letramento digital do professor, ou alfabetização tecnológica, não se limitando apenas ao uso mecânico dos recursos tecnológicos, e sim se estendendo à capacidade de entender, dominar e utilizar, na esfera da educação, as novas linguagens tecnológicas articuladas com o currículo e as estratégias didático-pedagógicas.

As referidas autoras esclarecem ainda que a ausência de uma formação adequada para a população usufruir dos recursos tecnológicos e compreender suas diversas linguagens poderá repercutir numa forma de desigualdade social envolvendo a relação homem-tecnologia. No entanto, não podemos negar que a escola se depara com algumas dificuldades em realizar essa formação devido a uma série de fatores políticos, sociais e econômicos, como a falta de prioridade das políticas públicas voltadas à implementação de ações na educação.

Com efeito, o aprofundado nível TPACK corresponde a uma permanente necessidade para os docentes em todos os níveis de ensino. Sob esse viés, um docente letrado digitalmente, comprometido e sintonizado com a cibercultura precisará, além da capacidade de análise crítica dessa sociedade tecnológica,

[...] de competências técnicas que o ajudem a compreender e organizar a lógica construída pelo aluno mediante sua vivência no meio social. Essa capacidade será necessária para utilizar as tecnologias e suas diferentes linguagens com o objetivo de atingir o aluno e transformá-lo em um cidadão também capaz de entender criticamente as mensagens dos meios de comunicação a que é exposto, além de saber lidar, no dia a dia, com os outros avanços tecnológicos que o rodeiam (SAMPAIO; LEITE, 1999, p. 19).

Percebe-se, assim, que a mera inserção de tecnologias na escola não garante que elas sejam utilizadas para favorecer uma educação de qualidade. Dessa forma, o processo de letramento digital do professor deve ocorrer desde a sua formação inicial, tendo em vista a necessidade de se levar em consideração a grande quantidade de informações que circulam no mundo em ritmo acelerado atualmente, o que exige cada vez mais dos educadores que busquem maneiras de agir pedagogicamente e em conjunto com a tecnologia, para que reflitam e dominem criticamente e não sejam dominados por ela.

Considerando que a atuação dos professores é fruto de sua formação desenvolvida desde o curso de licenciatura até os processos de educação continuada e suas experiências em sala de

\footnotetext{
5 Technological Pedagogical Content Knowledge - TPACK.
} 
aula, quanto mais cedo forem letrados tecnologicamente, maiores serão as possibilidades de esses profissionais analisarem e refletirem sobre as transformações da realidade, bem como de praticarem propostas pedagógicas inovadoras de acordo com as necessidades locais e globais. Sendo assim, tais medidas permitirão ao professor ter clareza do seu papel enquanto agente transformador, ajudando os discentes a construírem formas de encarar o mundo e aprender a lidar pacificamente com as tecnologias.

De maneira geral, o aperfeiçoamento do conhecimento pedagógico do conteúdo se efetivará e se consolidará por meio da prática docente, acerca da qual podemos considerar que o letramento digital implicará também sobre a capacidade desse profissional em "lidar com as diversas tecnologias e interpretar sua linguagem, além de distinguir como, quando e por que são importantes e devem ser usadas" (SAMPAIO; LEITE, 1999, p. 75). Em outras palavras, esse letramento está relacionado não apenas com o domínio das mais variadas tecnologias e suas linguagens, mas com uma constante prática de aperfeiçoamento técnico e pedagógico do professor, na qual o TPACK representa o conhecimento de que o professor necessita para poder utilizar com eficiência e de forma pedagógica as TMDIC em suas atividades docentes.

\section{Abordagem metodológica}

O presente estudo corresponde a uma derivação de outra pesquisa envolvendo o uso de cenários virtuais de aprendizagem com estudantes e professores da Educação Básica, submetido à Comissão de Ética e Pesquisa (CEP) da UFS e aprovado por ela, conforme o parecer $\mathrm{n}^{\circ}$ 3.773.965, o qual nos motivou a estender e adaptar essa investigação para o Ensino Superior.

Optamos por uma abordagem qualitativa e exploratória para analisar os fenômenos investigados, bem como interpretar as relações subjetivas existentes entre os sujeitos envolvidos e atribuir significados a elas. De acordo com Flick (2009, p. 23), os aspectos fundamentais da pesquisa qualitativa estão relacionados com a escolha adequada de "[...] métodos e teorias convenientes; reconhecimento e na análise de diferentes perspectivas; reflexões dos pesquisadores a respeito de suas pesquisas como parte do processo de produção de conhecimento; e com a variedade de abordagens e métodos".

Os sujeitos participantes deste estudo foram três professores/pesquisadores com notável experiência e importantes contribuições em pesquisas relacionadas com a formação docente e o uso das TMDIC na educação, que colaboraram especificamente no processo de validação qualitativa de um questionário, além da amostra com 33 (trinta e três) acadêmicos do Curso de Licenciatura em Ciências Biológicas da UFS, distribuídos em 11 (onze) matriculados na modalidade presencial e 22 na EaD. Esses licenciandos correspondem ao público-alvo da pesquisa e contribuíram na participação de estudo de caso. De acordo com Yin (2005), esse método permite investigar e preservar as características significativas dos fenômenos nos mais variados contextos sociais, permitindo aprofundar o conhecimento e subsidiar novas investigações.

Convém ressaltar que a oferta de curso de licenciatura em Ciências Biológicas da UFS é gerida pelo Departamento de Biologia (DBI), e deste estudo participou uma turma regularmente matriculada na modalidade presencial, no campus de São Cristóvão, e as demais na modalidade EaD, sendo estas coordenadas pelo Centro de Educação Superior a Distância (CESAD), criado em 2006, e vinculadas ao Sistema Universidade Aberta do Brasil (UAB) (RODRIGUES, 2018). Nesse sentido, os licenciandos participantes matriculados na modalidade $\mathrm{EaD}$ estavam vinculados a oito polos de apoio presencial, especificamente nos municípios de Brejo Grande, Japaratuba, Lagarto, Estância, Arauá, Propriá, São Domingos e 
Poço Verde, contemplando, assim, diversas realidades do Estado de Sergipe. Para facilitar a compreensão, na Figura 1, a seguir, é apresentado o mapa do Estado de Sergipe com a identificação dessas cidades que oferecem apoio presencial para os acadêmicos dos cursos na modalidade EaD.

Figura 1 - Distribuição das cidades/polos de apoio presencial das turmas na modalidade EaD

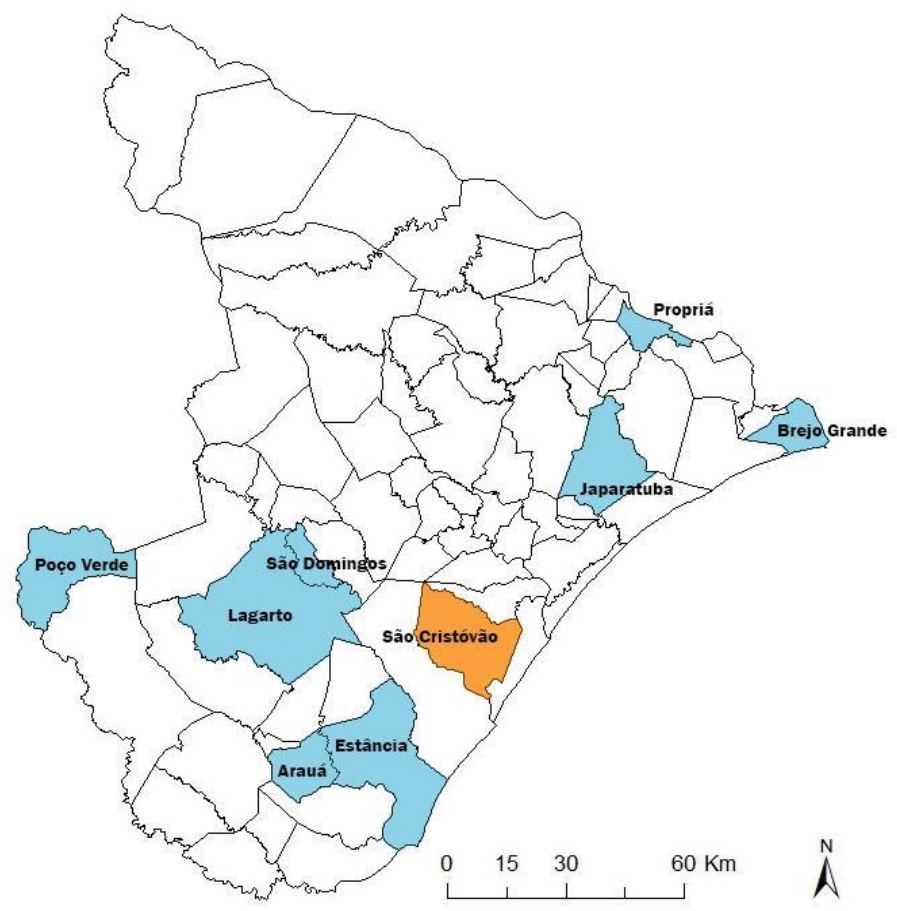

Fonte: Adaptada pelos autores (2020) com base cartográfica do IBGE.

Dentre os principais fatores que contribuíram para a realização desta pesquisa com o público-alvo, destacou-se a atuação voluntária de um dos autores como Professor Colaborador da disciplina 'Educação em Saúde' no curso presencial e como Professor Coordenador da disciplina 'Estágio Supervisionado II: no ensino de Ciências e Biologia', na modalidade EaD, o que possibilitou interação com os estudantes durante e após as aulas com a turma presencial, por meio do Ambiente Virtual da Aprendizagem (AVA) e durante os encontros presenciais com a turma da EaD. Quanto aos critérios de inclusão e exclusão desses participantes, foi estabelecida a inclusão de todos os licenciandos devidamente matriculados e que tivessem cursado pelo menos $75 \%$ da grade curricular, ou seja, matriculados do $6^{\circ}$ período em diante.

O estudo atendeu aos princípios éticos estabelecidos pelo Conselho Nacional de Saúde, respeitando a Resolução $n^{\circ}$ 510/2016, que trata das pesquisas com seres humanos. Os sujeitos foram convidados a participar da pesquisa por livre e espontânea vontade, demonstrada através de um Termo de Consentimento Livre e Esclarecido (TCLE), redigido em forma de carta convite, além de nos atentarmos para assegurar a confidencialidade e a privacidade dos indivíduos envolvidos, garantindo, assim, a proteção da sua imagem e o anonimato, bem como a liberdade de desistirem de prosseguir com a pesquisa a qualquer momento (BRASIL, 2016).

Para que um questionário e os demais instrumentos de avaliação adquiram confiabilidade e representatividade das respostas dos sujeitos envolvidos, é necessário se atentar a alguns processos de validação (PASQUALI, 2009; JESUS, 2013; ALVES, 2019). 
Nesta pesquisa, a validação qualitativa do questionário contou com a contribuição dos três pesquisadores citados e ocorreu em duas etapas para se obter um consenso satisfatório acerca dos critérios avaliados e se atender aos objetivos da pesquisa, como a compreensão da cultura digital desses acadêmicos e sua percepção acerca do uso das TMDIC no âmbito educacional e em sua formação. Esse instrumento foi desenvolvido através da plataforma de Formulários do Google, ou 'Google Forms', e sua versão final contou com 25 questões divididas em três seções: identificação dos participantes quanto a gênero, idade e período cursado; caracterização dos participantes quanto ao uso das TMDIC; e uso das TMDIC no processo de formação inicial docente. Além dessas questões objetivas, os acadêmicos foram convidados também, num segundo momento, a participarem de um roteiro de entrevista com mais três questões discursivas acerca de suas percepções sobre a utilização das TMDIC no âmbito educacional e suas observações durante o Estágio Supervisionado.

As questões foram predominantemente objetivas, todas de caráter pessoal e com base nas concepções e percepções dos respondentes; em algumas delas, optamos por uma escala do tipo Likert de quatro pontos para identificar as opiniões dos acadêmicos acerca da importância das tecnologias de maneira geral, sobretudo das TMDIC como proposta didático-pedagógica. De acordo com Richardson (2012), dentre os diversos instrumentos de coleta de dados, a aplicação de questionários é um dos mais comuns devido à possibilidade de descrever as características e mensurar determinadas variáveis de um grupo social.

No que se refere aos conteúdos coletados, nos baseamos em Bardin (2016) para realizar as análises dos dados produzidos durante a aplicação dos questionários. Para fins de consulta, apresentamos, na Figura 2, a seguir, um 'QR Code' (código QR - "Quick Response”), ou seja, um código de barras bidimensional, que dará acesso à versão final do questionário ${ }^{6}$ validado e aplicado na pesquisa.

Figura $2-Q R$ Code do questionário elaborado na pesquisa

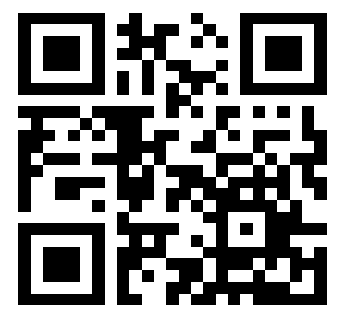

Fonte: Elaborado pelos autores (2020).

Após as devidas adequações, o questionário foi disponibilizado para os acadêmicos através do envio do link pelo aplicado WhatsApp e também na forma de convite na plataforma AVA do CESAD. A validação desse instrumento contribuiu para delimitar com clareza a natureza das questões, conforme as dimensões dos conceitos a serem verificados.

Corroborando essa discussão acerca das principais vantagens da utilização de questionários nas pesquisas, Richardson (2012) destaca também a possibilidade de se obter informações dos participantes em um tempo relativamente curto, bem como a facilidade de tabular esses dados. Nessa perspectiva, optamos pelo questionário on-line, considerando as

\footnotetext{
${ }^{6}$ Disponível em: https://drive.google.com/file/d/1FjWN91NpthZ7OIUdGKs31mWheOx3_J93/view. Acesso em: 13 ago. 2020.
} 

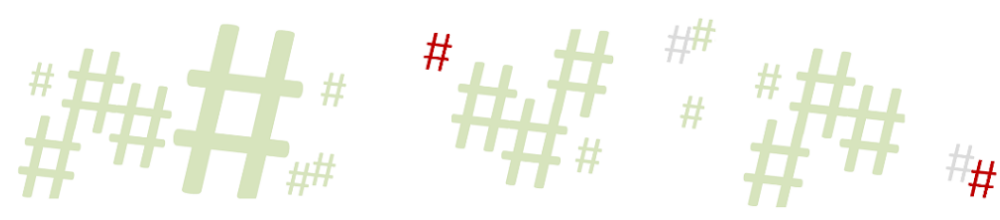

facilidades e comodidades proporcionadas pelas TMDIC, e Flick (2009, p. 32) contribui com essa ideia ao argumentar que "muitos dos métodos qualitativos existentes vêm sendo transferidos e adaptados às pesquisas que utilizam a internet como ferramenta, como fonte ou como questão de pesquisa".

\section{Principais resultados e discussões}

$\mathrm{O}$ uso de um questionário on-line contribuiu significativamente para a produção dos dados e para a realização da pesquisa, pois, considerando as várias localidades em que os acadêmicos residem, bem como suas duplas jornadas de trabalho e estudo, a aplicação presencial de um questionário demandaria mais tempo e poderia comprometer as aulas presenciais e até mesmo as atividades destinadas para os encontros presenciais da turma EaD. Esses benefícios eram esperados, visto que, de acordo com França, Ferrete e Gouy (2010) e Alves (2019), os recursos tecnológicos, quando aplicados de maneira correta nas pesquisas, correspondem a uma importante estratégia que está cada vez mais acessível para pessoas de modo geral, sem restrições de tempo e espaço, promovendo a comunicação mediante o uso de e-mail, WhatsApp, chat, entre outras plataformas e recursos.

Com base nos dados obtidos a partir do preenchimento do questionário, foi possível identificar algumas características dos licenciandos e assim traçar um perfil sociodemográfico desses participantes. Inicialmente, percebemos um acentuado desequilíbrio entre o quantitativo dos respondentes de acordo com o gênero, visto que a amostra dos 33 licenciandos foi constituída por 22 do sexo feminino $(66,7 \%)$ e 11 do sexo masculino $(33,3 \%)$. Com relação à faixa etária, a idade média geral dos sujeitos correspondeu a 35 anos, com predomínio para a faixa etária entre 29 e 30 anos, o que, na visão de Palfrey e Gasser (2011), caracteriza esses participantes, predominantemente, como imigrantes digitais. A distribuição dessa faixa etária está demonstrada no Gráfico 1, a seguir.

Gráfico 1 - Distribuição da faixa etária dos licenciandos quanto à modalidade de ensino

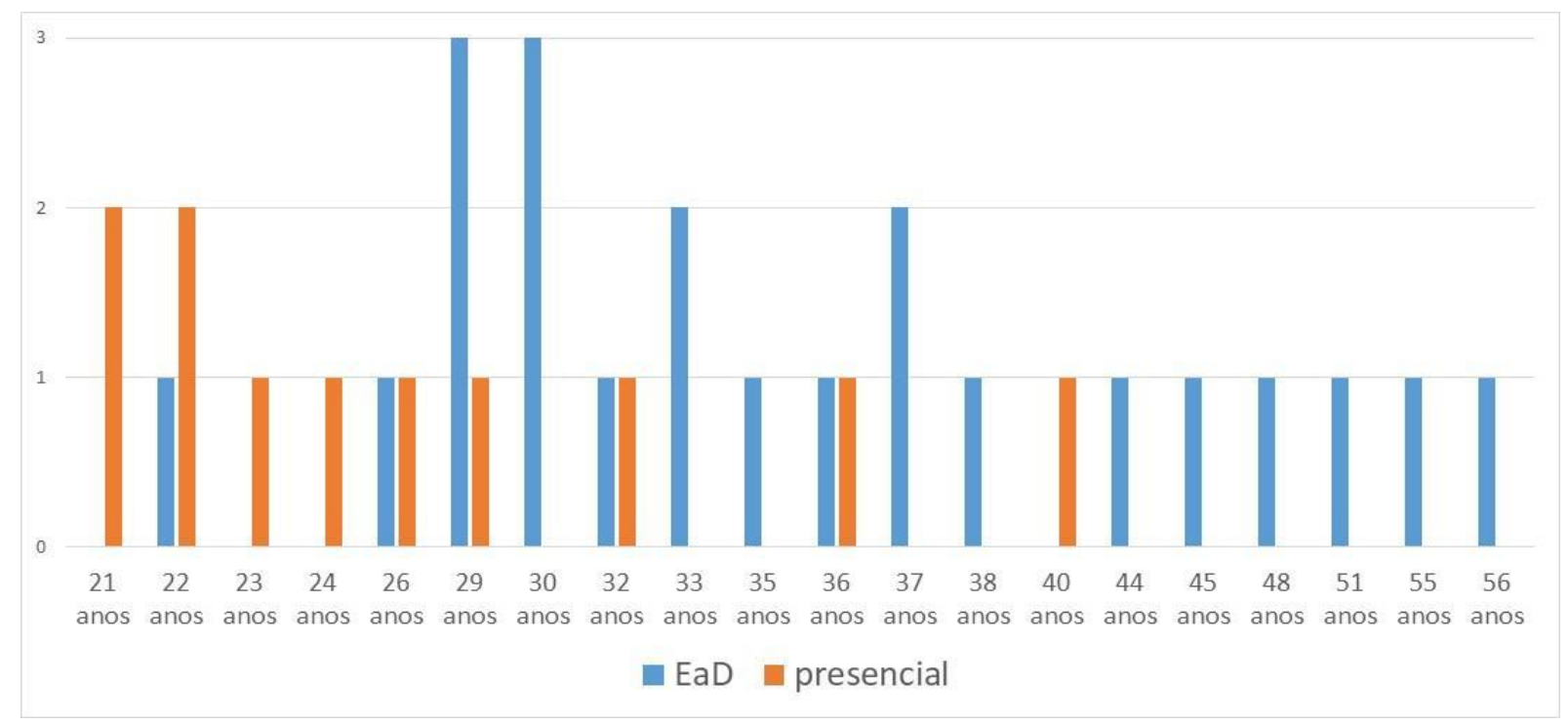

Fonte: Elaborado pelos autores (2019). 
Convém ressaltar que essas variações nas idades dos participantes, de 21 a 40 anos na modalidade presencial, e de 22 a 56 anos na modalidade EaD, evidenciam uma característica típica em comparação com essas duas modalidades, pois, embora o perfil desses públicos tenha sofrido mudanças nos últimos anos, Pavesi e Alliprandini (2014) apontam que o público dos cursos presenciais geralmente é mais jovem, enquanto que, nos cursos na modalidade EaD no país, boa parte dos estudantes é constituída por pessoas com idade mais elevada, que por algum motivo não conseguiram concluir os estudos antes e por isso recorreram à modalidade como uma alternativa para prosseguir com seus estudos.

Numa abordagem mais contemporânea, o Decreto $n^{\circ}$ 9.057, de 25 de maio de 2017, conceitua a $\mathrm{EaD}$ como uma modalidade educacional na qual a mediação didático-pedagógica nos processos de ensino e aprendizagem ocorre com a "utilização de meios e tecnologias de informação e comunicação, com pessoal qualificado, com políticas de acesso, com acompanhamento e avaliação compatíveis" (BRASIL, 2017). Esses pressupostos enfatizam a necessidade de um estudo mais independente, com o desenvolvimento da autonomia dos estudantes nos processos de aprendizagem.

No que se refere ao cumprimento dos componentes curriculares, a maioria dos licenciandos se encontrava em fase de conclusão de curso, com 21 deles $(63,6 \%)$ matriculados no oitavo (e último) período da graduação, e os demais no sétimo e sexto períodos, nove $(27,3 \%)$ e três $(9,1 \%)$, respectivamente. Nesse sentido, por serem graduandos que se encontravam, em sua quase totalidade, no último período do curso, constatamos que já tinham se deparado, durante seu processo de formação inicial, com as disciplinas didáticas e metodológicas, além de estágios supervisionados e inclusive práticas de residência pedagógica. Por esse motivo, analisar a percepção desses licenciandos sobre o uso das TMDIC em seu processo de formação foi de suma importância.

Quando questionados sobre suas opiniões referentes à inserção das TMDIC no ambiente escolar, todos os participantes concordaram que esses dispositivos contribuem para a aprendizagem dos educandos, desde que sejam utilizados adequadamente dentro e fora da sala de aula, por isso devem fazer parte da formação inicial e continuada dos professores. Pudemos observar essa concordância tanto no preenchimento do questionário, quanto por meio de entrevistas, como demonstrado nas narrativas das alunas 4 e 5 , a seguir.

\footnotetext{
A partir da utilização desses recursos, os alunos terão a oportunidade de aprofundar sobre o tema abordado em sala de aula e terão melhor desempenho na aprendizagem, por isso não faz sentido o professor não utilizar algum tipo de tecnologia em sala de aula, pois isso está intrínseco na sociedade (aluna 5).

Devem ser ofertados cursos complementares na área digital e incluídas disciplinas específicas na estrutura curricular dos futuros docentes. Além disso, projetos de conscientização sobre a importância e os benefícios do uso das tecnologias em sala de aula (aluna 4).
}

No entanto, nove desses licenciandos $(27,3 \%)$ relataram que não foram trabalhadas propostas de utilização dessas tecnologias em sala de aula durante sua formação na universidade, demonstrando, assim, uma importante fragilidade na perspectiva da formação inicial de professores à luz da cultura digital.

Com efeito, quando questionados sobre os fatores que poderiam ter dificultado a abordagem das TMDIC no seu curso de licenciatura, a maioria dos participantes citou a falta de interesse dos professores da universidade, inclusive de alguns tutores, bem como a falta de 
motivação da turma e a carência de recursos didáticos e tecnológicos, como acesso à internet, entre outros. Alguns participantes relataram também a falta de capacitação dos seus professores e tutores em explorar os recursos do AVA, a quantidade reduzida de encontros presenciais e a própria dificuldade em utilizar as TMDIC no cotidiano como possíveis limitações que dificultaram a implementação de propostas didáticas envolvendo essas tecnologias móveis em sua formação inicial. Essa discussão reafirma alguns resultados encontrados por Santos, Ferrete e Alves (2020, p. 23) num estudo bibliográfico envolvendo relatos de experiências docentes, no qual se percebeu que a "ausência de abordagens tecnológicas, tanto nos cursos de formação de professores em nível das licenciaturas, quanto nos cursos de formação continuada" é uma realidade decorrente de diversos fatores, como a falta de recursos e até mesmo a falta de conhecimento ou habilidade para utilizar a tecnologia de maneira aliada e integrada ao trabalho pedagógico.

Nessa perspectiva, para verificar como os licenciandos participantes da pesquisa, apesar de a maioria cursar uma graduação na modalidade $\mathrm{EaD}$, avaliavam seu grau de familiaridade e domínio com relação ao uso das TMDIC, bem como a frequência com que faziam uso dessas tecnologias em suas práticas cotidianas, as questões submetidas foram de cunho pessoal e nos permitiram, de certa forma, conhecer aspectos da cultura digital desses participantes. Alguns desses dados estão apresentados na Tabela 1, a seguir.

Tabela 1 - Frequência das respostas quanto ao domínio e à utilização das TMDIC

\begin{tabular}{|c|c|c|c|c|}
\hline QUESTÕES & Insuficiente & Pouco & Satisfatório & Avançado \\
\hline \multirow[t]{2}{*}{$\begin{array}{l}\text { Como você avalia seus conhecimentos e habilidades } \\
\text { para lidar com as TMDIC no dia a dia? }\end{array}$} & - & $5(16 \%)$ & $21(64 \%)$ & $7(21 \%)$ \\
\hline & Até 1x/sem. & $\begin{array}{l}\text { De } 2 \text { a } \\
4 x / \text { sem. }\end{array}$ & $\begin{array}{l}\text { De } 4 \text { a } \\
6 x / \text { sem. }\end{array}$ & $\begin{array}{l}\text { Todos os } \\
\text { dias }\end{array}$ \\
\hline $\begin{array}{l}\text { Com que frequência você utiliza o computador ou } \\
\text { notebook? }\end{array}$ & $2(6,0 \%)$ & $8(24 \%)$ & $8(24 \%)$ & $15(46 \%)$ \\
\hline Com que frequência você utiliza a internet? & - & $2(6 \%)$ & $3(9 \%)$ & $28(85 \%)$ \\
\hline Com que frequência você utiliza o smartphone? & $1(3 \%)$ & $1(3 \%)$ & $1(3 \%)$ & $30(91 \%)$ \\
\hline Com que frequência você utiliza o tablet? & $26(79 \%)$ & $2(6 \%)$ & $2(6 \%)$ & $3(9 \%)$ \\
\hline
\end{tabular}

Fonte: Elaborada pelos autores (2019).

Ao analisarmos esses dados, é possível observar que 28 dos licenciandos (85\%), considerando os níveis satisfatório e avançado, afirmaram possuir conhecimentos e habilidades sobre a utilização das TMDIC em seu cotidiano, contudo os outros cinco (16\%) relataram possuir pouco domínio, o que pode ser interpretado como certa dificuldade em manusear essas tecnologias. Inferimos, assim, que o fato de alguns serem imigrantes digitais, juntamente com possíveis dificuldades de acesso a essas tecnologias no decorrer de suas vivências profissionais e acadêmicas, tem contribuído para essa realidade. Quanto à frequência do uso desses dispositivos, a maioria (mais de 80\%) relatou acessar a internet todos os dias da semana, sendo o smartphone o dispositivo mais utilizado. Ainda nesse bloco de questões, a maioria dos acadêmicos referiu acessar a internet no ambiente domiciliar, outros referiram acessar a rede 
na universidade e/ou no trabalho, apontando uma interconexão desses participantes com o ciberespaço.

Quanto à finalidade do acesso à internet desses licenciandos, observamos uma variedade de respostas, como podemos observar no Gráfico 2, a seguir.

Gráfico 2 - Frequência das finalidades quanto ao uso da internet pelos participantes

33 respostas

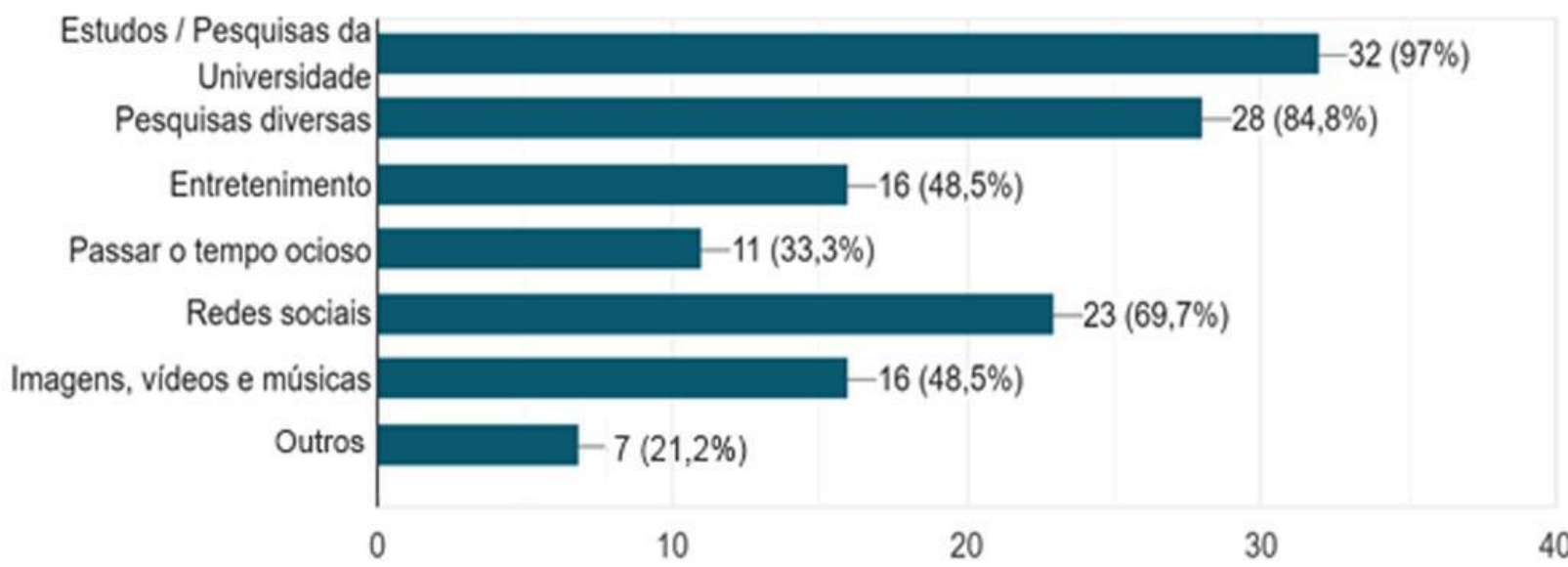

Fonte: Elaborado pelos autores (2019).

Observamos que praticamente todos os participantes (97\%) informaram utilizar a internet para fins de estudos e realização de pesquisas da universidade; muitos informaram realizar pesquisas diversas e apenas 11 estudantes $(33,3 \%)$ relataram passar o tempo ocioso navegando na internet. Esses perfis podem ser um retrato dos cursos de $\mathrm{EaD}$ em comparação com os presenciais, em que o acadêmico muitas vezes precisa assumir uma postura autônoma e responsável em estar buscando meios, fazendo pesquisas e demais estratégias para superar dúvidas e aprimorar a aprendizagem. Percebemos, ainda, que mais da metade dos participantes informou fazer uso das redes sociais e, quando solicitado que marcassem quais as mídias, plataformas e redes sociais eram mais utilizadas por eles, notamos que a maioria indicou o WhatsApp, seguido do Google Acadêmico, e-mail, YouTube, Instagram e Facebook, dados esses que nos mostram que, apesar de a turma possuir boa parte de imigrantes digitais, a cultura digital está presente na vida desses sujeitos.

Ao serem indagados, durante a entrevista, sobre quais motivos poderiam ser considerados importantes para se abordar o uso das TMDIC nos cursos de licenciatura enquanto práticas didático-pedagógicas, todos os participantes consideraram relevante englobar essa abordagem tecnológica ao longo de sua formação inicial, tendo em vista a necessidade dos educadores acompanhar e atender as demandas inerentes da cultura digital, tanto no âmbito escolar quanto em seu cotidiano. Apresentamos, a seguir, algumas das narrativas que evidenciam o interesse desses licenciandos no que se refere ao letramento digital docente.

É importante que os professores estejam atentos às novas tecnologias que vêm crescendo cada dia, e com bastante frequência, para que possamos estar atualizados diante de tanta modernidade no mundo das tecnologias e, assim, poder acompanhá-la para colocar em prática nas aulas (aluno 16). 
As abordagens tecnológicas [...] precisam fazer parte do processo permanente de aperfeiçoamento dos saberes necessários à atividade docente, realizado ao longo da vida profissional, com o objetivo de assegurar uma ação docente efetiva e que promova aprendizagens significativas (aluno 18).

Ampliando essa discussão, quando questionados sobre suas vivências durante a realização dos estágios supervisionados, a maioria dos licenciandos (67\%) informou ter observado que os professores regentes faziam uso das TMDIC nas aulas, sendo que a maior frequência relatada dessa prática foi de uma a duas vezes ao mês. E, quando questionados sobre quais recursos tecnológicos foram utilizados por esses professores durante o período do estágio, a maioria relatou que se tratava apenas do uso do notebook e do projetor (também conhecido como Datashow) para apresentação de slides ou outras multimídias de imagens, vídeos e sons. Apenas oito dos licenciados (24\%) relataram ter percebido a utilização dos recursos do 'Google Sala de Aula' (G. Suite for Education) pelos professores regentes, e nenhum acadêmico relatou ter observado o uso de aplicativos educacionais nesse período.

Ao analisar todas essas discussões, percebemos que os licenciandos têm uma visão crítica quanto à necessidade de se trabalhar com as tecnologias no processo de formação inicial docente, considerando as exigências do cenário contemporâneo marcado pela ênfase da cultura digital, na qual algumas lacunas foram apontadas quando eles relataram dificuldades ou ausência dessas abordagens enquanto propostas didático-metodológicas em seu processo de formação. Observamos também que houve um consenso dos participantes ao considerarem os benefícios do uso das TMDIC no âmbito educacional, tendo em vista a melhoria do processo de aprendizagem dos alunos e da prática docente.

\section{Considerações finais}

Diante das discussões levantadas, não há dúvidas de que as tecnologias em geral, sobretudo as TMDIC, quando utilizadas de maneira consciente e responsável, contribuem essencialmente para a formação crítica e cidadã dos sujeitos, sendo que a escola, enquanto instituição social responsável pelo desenvolvimento intelectual e atitudinal dos alunos, precisa promover o domínio dessas tecnologias. Por esse motivo, o letramento digital do professor deve estar alinhado a um trabalho educativo significativo para poder lidar com as diversas tecnologias desde o processo de formação inicial, interpretando suas linguagens e criando novas formas de expressão para promover uma aprendizagem mais expressiva.

Embora a cultura digital se faça presente em todas as dimensões da dinâmica social contemporânea, marcada por uma série de transformações decorrentes da evolução tecnológica que ajudam os indivíduos a enfrentarem os desafios do século XXI, foram constatadas neste estudo algumas barreiras que dificultam a inserção ou a continuidade de abordagens envolvendo essas tecnologias nos cursos de Licenciatura em Ciências Biológicas da UFS, tendo em vista que alguns acadêmicos relataram que, mesmo diante dessas revoluções tecnológicas, as propostas didático-metodológicas envolvendo as TMDIC ainda são ausentes ou escassas em sua formação.

De maneira geral, as tecnologias têm um papel fundamental na vida das pessoas, principalmente no que diz respeito às formas de comunicação, à produção de conhecimentos, à resolução de problemas e à disseminação de informações. No entanto, para que esses benefícios 
sejam consolidados, é necessário que os sujeitos utilizem as tecnologias digitais de maneira ética, qualificada e reflexiva nas diferentes práticas sociais.

Nesse sentido, o letramento digital docente precisa ser compreendido como uma necessidade contínua que se traduz em uma percepção plena do papel das tecnologias na organização do mundo atual, sobretudo na capacidade do professor em lidar com as diversas tecnologias e de promover novas formas de expressão e interação para serem utilizadas no processo educativo. Finalmente, foi constatado que desde a formação inicial faz-se necessário abordar conhecimentos e instrumentos didático-pedagógicos voltados ao uso das TMDIC, no entanto este estudo constatou que uma parcela significativa dos participantes relata a insuficiência ou até mesmo a ausência dessas abordagens em sua formação.

\section{Referências}

ALVES, M. M. S. Vulnerabilidade às IST/AIDS: desenvolvimento e validação de um instrumento de avaliação inspirado nas questões sociocientíficas. 2019. 217p. Dissertação (Mestrado em Ensino de Ciências e Matemática) - Universidade Federal de Sergipe, São Cristóvão, SE, 2019.

ANDRÉ, M. E. D. A. de. Estudo de caso em pesquisa e avaliação educacional. Brasília: Líber Livro Editora, 2005. 68p.

BARCELOS, G. T. Redes sociais e formação de professores. Perspectiva online, v. 5, n. 2, p. 5-10, 2012. Disponível em:

https://ojs3.perspectivasonline.com.br/humanas_sociais_e_aplicadas/article/view/62/41. Acesso em: 17 abr. 2020.

BARDIN, L. Análise de conteúdo. Tradução Luís Antero Reto, Augusto Pinheiro. São Paulo: Edições 70, 2016. 279p.

BRASIL. Base Nacional Comum Curricular: Educação Infantil, Ensino Fundamental e Ensino Médio. Brasília: MEC/Secretaria de Educação Básica, 2018. Disponível em: http://basenacionalcomum.mec.gov.br/images/BNCC_EI_EF_110518_versaofinal_site.pdf. Acesso em: 11 abr. 2020.

BRASIL. Conselho Nacional de Saúde. Resolução nº 510, de 07 de abril de 2016. Disponível em: https://bvsms.saude.gov.br/bvs/saudelegis/cns/2016/res0510_07_04_2016.html. Acesso em: 21 abr. 2020.

BRASIL. Decreto $\mathrm{n}^{\circ}$ 9.057, de 25 de maio de 2017. Diário Oficial da União. Disponível em: http://www.planalto.gov.br/ccivil_03/_ato2015-2018/2017/decreto/d9057.htm. Acesso em: 21 abr. 2020.

BRASIL. Portaria No 343, de 17 de março de 2020. Diário Oficial da União. Disponível em: http://www.in.gov.br/web/dou/-/portaria-n-343-de-17-de-marco-de-2020-248564376. Acesso em: 21 abr. 2020.

BRASIL. Lei de Diretrizes e Bases da Educação Nacional. Nº 9.394/96. Brasília: Congresso Nacional/MEC, 1997. Disponível em: 
https://www2.senado.leg.br/bdsf/bitstream/handle/id/70320/65.pdf?sequence=3. Acesso em: 11 abr. 2020.

CASTELLS, M. A sociedade em rede. 2. ed. São Paulo: Paz e Terra, 1999. 455p. v.1

CIBOTTO, R. A. G.; OLIVEIRA, R. M. M. A. O conhecimento tecnológico e pedagógico do conteúdo (TPACK) na formação inicial do professor de matemática. In: VIII Encontro de Produção Científica e Tecnológica - EPCT. Campo Mourão. Anais..., 2013.

CRUZ, P.; BORGES, J. M.; NOGUEIRA FILHO, O. Nota técnica: ensino a distância na Educação Básica frente à pandemia da Covid-19. Todos pela Educação, abr. 2020.

Disponível em: https://www.todospelaeducacao.org.br/_uploads/_posts/425.pdf. Acesso em: 11 out. 2020.

FERRETE, A. A. S. S.; FERRETE, R. B. Tecnologias móveis no ambiente escolar: desafios e reflexões. $3^{\circ}$ Congresso Brasileiro de Informática na Educação (CBIE 2014). In: Anais... p. 360-369, 2014.

FERRETE, A. A. S. S.; FERRETE, R. B. As tecnologias móveis na formação docente. IV Congresso Brasileiro de Informática na Educação (CBIE 2015). In: Anais... p. 844-853, 2015.

FERRETE, A. A. S. S.; FERRETE, R. B. As tecnologias móveis digitais nos cursos de licenciatura. VI Congresso Brasileiro de Informática na Educação (CBIE 2017). In: Anais... p. 584-593, 2017a.

FERRETE, A. A. S. S.; FERRETE, R. B. Formação docente: percepções dos professores sobre o uso das tecnologias móveis digitais no processo de ensino e aprendizagem. VI Congresso Brasileiro de Informática na Educação (CBIE 2017). In: Anais... p. 515-523, $2017 b$.

FLICK, U. Introdução à pesquisa qualitativa. Tradução Joice Elias Costa. 3. ed. Porto Alegre: Artmed, 2009. 405p.

FRANÇA, L. C. M.; FERRETE, A. A. S.; GOUY, G. B. Educação à distância: ambientes virtuais, TIC e universidades abertas. Aracaju: Criação, 2010. 106p.

GARCIA, R. P. M. Interatividade: uma estratégia de negociação em prol da avaliação na educação a distância. In: BURNHAM, T. F.; MATTOS, M. L. P. (org.). Tecnologias da informação e educação à distância. 2. ed. Salvador: EDUFBA, 2010.

GEWEHR, D. Tecnologias digitais de informação e comunicação (TDICs) na escola e em ambientes não escolares. 2016. 137 p. Dissertação (Programa de Pós-Graduação Stricto Sensu Mestrado em Ensino) - Centro Universitário UNIVATES, Lajeado, 2016. Disponível em: https://www.univates.br/bdu/bitstream/10737/1576/1/2016DiogenesGewehr.pdf. Acesso em: 11 maio 2019.

JESUS, E. M. S. Desenvolvimento e validação de conteúdo de um instrumento para avaliação da assistência farmacêutica em hospitais de Sergipe. 2013. 152p. Dissertação (Mestrado em Ciências Farmacêuticas) - Universidade Federal de Sergipe, São Cristóvão, SE, 2013. 
KENSKI, V. M. Tecnologias e ensino presencial e à distância. Campinas: Papirus, 2003.

LEMOS, A. Cibercultura: tecnologia e vida social na cultura contemporânea. 7. ed. Porto Alegre: Sulina, 2015. 295p.

LÉVY, P. Cibercultura. Tradução: Carlos Irineu da Costa. 2. ed. São Paulo: Edições Loyola, 1999.

LUCENA, S. Culturas digitais e tecnologias móveis na educação. Educar em Revista, Curitiba, n. 59, p. 277-290, jan./mar., 2016.

MARINHO, S. P. P.; COSTA, F. J.; CARNEIRO, F. C.; OLIVEIRA, P. A.; NICOLAU, R. Tecnologias móveis, mídias e redes sociais: cultura de uso de estudantes de licenciatura. IV Congresso Brasileiro de Informática na Educação (CBIE 2015). In: Anais... p. 834-843, 2015.

MATTAR, João. Tutoria e interação em educação a distância. São Paulo: Cengage Learning, 2012.

MISHRA, P.; KOEHLER, M. J. Technological Pedagogical Content Knowledge: A Framework for Teacher Knowledge. Teachers College Record, v. 108, n. 6, p. 1017-1054, 2006. Disponível em: http://equella.cpit.ac.nz/cpit/file/8db8d22d-cd65-42c0-a6e7cad799d45993/1/TPAC_Model_Mischa_and_Koehler_2006.pdf. Acesso em: 2 mar. 2019.

OLIVEIRA, E. Conselho Nacional de Educação aprova juntar anos letivos de 2020 e 2021 e ensino remoto até fim do ano que vem [on-line], out. 2020. Disponível em: https://g1.globo.com/educacao/noticia/2020/10/06/cne-aprova-ensino-remoto-ate-dezembrode-2021-e-fusao-de-anos-letivos.ghtml. Acesso em: 13 out. 2020.

PALFREY, J.; GASSER, U. Nascidos na Era Digital: entendendo a primeira geração de nativos digitais. [S.1]: Artmed, 2011.

PASQUALI, L. Psicometria. Rev. Esc. Enferm. USP, v. 43 (Esp.), p. 992-999, 2009.

PAVESI, M. A. M.; ALLIPRANDINI, P. M. Z. Indicativos do perfil do aluno da educação a distância (EAD) e nível de aprendizagem autorregulada: uma análise descritiva. X ANPED SUL, Florianópolis, out. 2014. Disponível em: http://xanpedsul.faed.udesc.br/arq_pdf/5060.pdf. Acesso em: 17 set. 2020.

PECI, A. Ações e Estratégias COVID-19 [on-line]. Rev. de Adm. Pública (RAP). SciELO em Perspectiva, 2020. Disponível em: https://blog.scielo.org/blog/2020/03/30/rap-acoes-eestrategias-covid-19/. Acesso em: 19 abr. 2020.

PRODUÇÃO Científica e Tecnológica - EPCT, 2013.

RICHARDSON, R. J. Pesquisa social: métodos e técnicas. 3. ed. São Paulo: Atlas, 2012.

ROCHA, M. A.; SALVI, R. F. O conhecimento tecnológico pedagógico do conteúdo como aporte para o emprego das tecnologias digitais de informação e comunicação no ensino de geografia. Girando, Rio de Janeiro, v. 3, n. 5, p. 57-68, jan./jun. 2016. Disponível em: http://www.cp2.g12.br/ojs/index.php/GIRAMUNDO/article/viewFile/1356/988. Acesso em: 21 ago. 2020. 
RODRIGUES, B. M. Interfaces interativas nos processos comunicacionais do curso de química. 2018. 171p. Dissertação (Mestrado em Ensino de Ciências e Matemática) Universidade Federal de Sergipe, São Cristóvão, SE, 2018.

SAMPAIO, M. N.; LEITE, L. S. Alfabetização tecnológica do professor. 3. ed. Petrópolis: Vozes, 1999.

SANTAELLA, L. A aprendizagem ubíqua na educação aberta. Revista Tempos e espaços em educação, v. 7, n. 14. set/dez. 2014.

SANTO, E. E.; CARDOSO, A. L.; SANTOS, A. G. Conhecimento Tecnológico Pedagógico do Conteúdo (TPACK): um estudo em uma instituição de ensino superior público. CIET: EnPED, [S.1.], maio 2018. Disponível em:

https://cietenped.ufscar.br/submissao/index.php/2018/article/view/264. Acesso em: 21 ago. 2020.

SANTOS, W. L.; FERRETE, A. A. S. S.; ALVES, M. M. S. A produção do conhecimento sobre Facebook e educação no portal de periódicos da CAPES: relatos de experiências docentes. Revista Exitus, v. 10, p. 01-28, 2020. Disponível em:

http://www.ufopa.edu.br/portaldeperiodicos/index.php/revistaexitus/article/view/1255/691.

Acesso em: 21 mar. 2020.

SHULMAN, L. Knowledge and teaching: Foundations of the new reform. Harvard Educational Review, v. 57, n. 1, feb. 1987. Disponível em:

http://gse.buffalo.edu/fas/yerrick/ubscience/UB_Science_Education_Goes_to_School/21C_Li terature_files/shulman,\%201987.pdf. Acesso em: 10 fev. 2019.

SILVA, E. G. M.; MORAES, D. A. F. O uso pedagógico das TDIC no processo de ensino e aprendizagem: caminhos, limites e possibilidades. [S.1]: Cadernos PDF - Governo do Estado do Paraná, 2014.

TEIXEIRA, S. A. Fazendo pesquisa escolar na Internet. 2011. 175p. Dissertação (Programa de Pós-graduação em Estudos Linguísticos) - Universidade Federal de Minas Gerais, UFMG, Belo Horizonte, 2011.

ULIANO, K. C. M. L. Tecnologia Digital de Informação e Comunicação (TDIC) na educação: aplicativos e o mundo tecnológico no contexto escolar. 2016. 50p. Monografia (Especialização em Educação na Cultura Digital) - Universidade Federal de Santa Catarina (UFSC), Florianópolis, SC, 2016. Disponível em:

https://repositorio.ufsc.br/xmlui/bitstream/handle/123456789/169814/TCC_Uliano.pdf?seque nce=1\&isAllowed=y. Acesso em: 10 fev. 2019.

YIN, R. K. Estudo de caso: planejamento e métodos. 3. ed. Porto Alegre: Bookman, 2005. 212p.

Recebido em agosto de 2020.

Aprovado em novembro de 2020. 